\title{
The cost of health-related brain drain to the WHO African Region
}

\author{
Joses M Kirigia $^{1 *}$ Akpa R Gbary ${ }^{1}$, Jennifer Nyoni ${ }^{1}$, Anthony Seddoh ${ }^{1}$, Lenity K Muthuri ${ }^{2}$ \\ 1. World Health Organization, Regional Office for Africa, Brazzaville, Congo; 2. School of Public Health, Kenyatta \\ University, Nairobi, Kenya
}

\begin{abstract}
* Corresponding author: Health Financing and Social Protection Unit, Division of Health Systems Development and Services Delivery, WHO/AFRO, B.P. 06, Brazzaville, Congo. Tel: +47-241-39342.
\end{abstract}

\{Email: kirigiaj@afro.who.int\}

\section{SUMMARY}

The African Region continues to experience loss of a sizeable number of highly skilled health professionals (physicians, nurses, dentists and pharmacists) to Australia, North America and European Union. Past attempts to estimate cost of migration were limited to education cost only and did not include the lost returns from investment. The objective of this study was to estimate the social cost of emigration of doctors and nurses from the African Region to the developed countries. The cost information used in this study was obtained from one nonprofit primary and secondary school and one public university in Kenya. The cost estimates represent unsubsidized cost. The loss incurred by African countries through emigration is obtained by compounding the cost of educating a medical doctor and a nurse over the period between the age of emigration and the retirement age in recipient countries. The main findings were as follows: total cost of educating a single medical doctor from primary school to university is US $\$ 65,997$; for every doctor that emigrates, a country loses about US\$1,854,677 returns from investment; total cost of educating one nurse from primary school to college of health sciences is US\$43,180; for every nurse that emigrates, a country loses about US\$1,213,463 returns from investment. Developed countries continue to deprive African countries of billions of dollars worth of invaluable investments embodied in their human resources. If the current trend of poaching of scarce human resources for health (and other professionals) from African countries is not curtailed, the chances of achieving the Millennium Development Goals would remain dismal. Such continued plunder of investments embodied in human resources contributes to further underdevelopment of Africa and to keeping majority of her people in the vicious circle of poverty. Therefore, both developed and developing countries need to urgently develop and implement strategies for addressing this issue.

[Afr J Health Sci. 2006; 13:1-12]

\section{Introduction}

The WHO African Region continues to experience loss of a sizeable number of highly skilled health professionals (physicians, nurses, dentists and pharmacists) to Australia, North America and European Union. There are three categories of emigrants: scientific trainees (Masters and $\mathrm{PhD}$ level) who go overseas for training but fail to return upon completion of their studies; health professionals who train in developed countries, return upon completion of their studies, and then emigrate after working for some duration; and health professionals who train in local institutions but emigrate upon completion of their studies or after working for some period of time.

The causes of the first category of emigration include: lack of research funding; poor research facilities; limited career structures; poor intellectual stimulation; threats of violence; lack of good education for children in home country [1,2]; and lack of evidence-based decision-making culture leading to lack of recognition of the potential contribution of researchers to national health development. The second and third categories of emigration result from a combination of push (in source countries) and pull (in recipient countries) factors. The key push factors include: weak health systems; insecurity, including violence in the workplace; poor living conditions; low remunerations; lack of professional development opportunities, e.g. continuing education or training; lack of clear career development paths [3]; and risk of HIV infection due to lack of appropriate protective gear when handling specimens such as blood and 
blood products; nepotism in recruitment and promotion; political unrest/civil wars; wide-spread poverty; poor governance; and case overload.

Some of the factors that pull those professionals to developed countries may include: information, communication and technology making it easy to access information on jobs, visa applications and process; aggressive targeted recruitment to fill vacancies in richer countries; availability of employment opportunities; better remunerations and working conditions [4]; secure and conducive living conditions; and opportunities for intellectual growth, e.g. refresher courses, access to internet and modern library facilities. The push and pull factors in tandem have led to brain drain of health professionals from African countries. This has exacerbated the already weak national and district health systems, making it extremely difficult for countries in the Region to achieve the United Nations Millennium Development Goals [5,6].

This paper attempts to estimate the social cost of emigration of doctors and nurses from the African Region to the developed countries. The analysis is based on countries for whose international migration data were available.

\section{Methods}

\section{Conceptual Framework for production of health professionals}

Figure 1 presents a production function of schools that produce health professionals (medical doctors, dentists, nurses, paramedics and technicians), whereby different inputs (Box A) are combined in school process (Box B) to yield the specific outputs (Box C) and outcomes/benefits (Box D).

Each school uses recurrent and capital resources/inputs in Box A to produce health professionals. The recurrent/variable inputs (whose useful life is less than 1 year) include different categories of personnel, e.g. full-time and part-time employees, consultants, and volunteers; materials/supplies, e.g. text books and other printed material, paper, note books, overhead transparencies, chalk, dusters, cleaning materials, detergents, diagnostic supplies; utilities, e.g. electricity, water, gas, telephone, internet, facsimile, telex; travel and transport; family inputs, e.g. bus fare, tuition fees, living expenses; operating (e.g. fuel, insurance, registration and road licence fees) and maintenance (e.g. tyres, batteries, spare parts, repair of broken windows, furniture, plumbing, roofing) of capital inputs. The cost of each type of recurrent input is derived by multiplying the quantity used by market price per unit (unit cost).
The capital/fixed inputs (whose useful life is longer than 1 year) include buildings, equipment and vehicles. The economic cost of using capital inputs consists of (i) the opportunity cost of resources invested in its purchase; and (ii) the depreciation (wear and tear). The cost of a capital input equals its replacement value (price of a new item) divided by an annuity factor (usually obtained from an annuity table) to obtain cost per year [7,9]. Indirect cost refer to monetary value of productive or leisure time lost while undergoing training. This includes the opportunity cost of students time (since they would have been performing other activities if not studying) and time of family and friends that visit students. Thus, the total cost would be the sum of recurrent cost, capital cost and indirect costs (or productivity losses). However, since medical and nursing schools produce other outputs (e.g. research), we would need to apportion the total cost of running the school between production of graduates and research. We then multiply the annual cost of producing all graduates by the duration of training. In order to derive the average cost of training a health professional we divide the total cost of producing graduates per year by the number of students graduating in a given year.

In the context of brain drain, to get the grand average cost of producing a health professional, we will need to add to the average cost of medical and nursing schools, the average costs of primary-, secondary- and high school. That would give us an approximation of total cost of investment made by the society into, for example, the training of either a medical doctor or a nurse. Furthermore, it would be necessary to multiply the grand cost of educating a health professional by a compounding factor in order to obtain the returns from investment foregone by society when a health professional emigrates. In algebraic terms, the lost return from education investment into $\mathrm{a} \mathrm{i}^{\text {th }}$ doctor or nurse ( ILOSS $_{i=\text { Doctor, nurse }}$ ) who decide to emigrate would be:

$$
I L O S S_{i=\text { Doctor }, \text { nurse }}=A T C_{i, . .} \times(1+r)^{t}
$$

where: $A T C_{i, . .}=$ average total cost of educating a $i^{\text {th }}$ health professional, e.g. doctor, nurse; $(1+r)^{t}$ is the compounding factor; ' $r$ ' is the interest rate; and ' $t$ ' is the difference between average retirement age and average age at emigration.

\section{Data}

The data on cost of non-boarding primary and secondary education was obtained from one nonprofit religious mission school in Nairobi, Kenya. 
The primary school period is for eight years. The cost consists of tuition, lunch, transport, textbooks, stationary and uniforms. Appendix 1 presents the primary school cost break down per student. The tuition and lunch cost does not contain any subsidy.

Secondary school period is four years. The cost consists of tuition, lunch, transport, textbooks, stationary and uniforms. Appendix 2 presents the secondary school cost break down per student. The fees levied by the mission school aims at covering the cost, not making a profit. The data used to estimate the cost of training nurses and doctors were obtained from a Kenyan public university medical school and college of health sciences parallel (unsubsidised) programmes. The nursing programme is made up of four years of residence training and one year of internship. The cost estimates are made up of unsubsidised tuition fees, accommodation and living expenses. Appendix 3 presents a breakdown of the University of Nairobi cost per nursing student. The statistics on the number of African countries nurses registering with the United Kingdom Nursing and Midwifery Council (NMC) were obtained from NMC report for 2005 [10].

The medical doctor programme consists of five years of residence and one year of internship. The cost estimates are made up of unsubsidised tuition fees, accommodation and living expenses. Appendix 4 presents a breakdown of the University of Nairobi cost per medical student. The number of African doctors immigrating to various developed countries was obtained from Awases et al [3].

\section{Results}

\section{Economic loss due to emigration of doctors}

As shown in Table 1 a total of approximately 18,960 medical doctors from 14 African countries work in developed countries. About 54.2\% of them work in the United Kingdom, $28.3 \%$ work in the USA, $10.3 \%$ work in Canada, $4.8 \%$ work in Australia, 1.4\% work in Portugal and 1\% work in Germany [3]. The cost of tertiary education of a single doctor in Kenya is approximately US\$48,169. The total cost of secondary education per student is US\$6,865 and that for primary education US\$10,963 per student. Thus, the total education cost per medical doctor is US\$65,997 (i.e. US\$48169+US\$6,865+US\$10,963). That figure does not represent the loss incurred by society as a result of emigration of a single medical doctor. The real loss is the dollar value of the alternative use of the resources invested in producing a doctor, i.e. the opportunity cost.

Lets assume that the average age of emigrating doctors is 30 years [3]; retirement age is 65 years in recipient countries; an emigrant doctor would work for 35 years before retirement; and market interest rate for fixed deposits is $10 \%$ per year [7-9]. If the US\$65,997 (i.e. cost of educating one medical doctor) were put into a commercial bank for a period of 35 years, at a fixed deposit interest rate of $10 \%$ per annum, the investment will have grown to US $\$ 1,854,677$. This is obtained by applying the standard compounding formula: [(initial investment) $\left.\mathrm{x}(1+\mathrm{r})^{\mathrm{t}}\right]=\left[\mathrm{US} \$ 65,997 \times(1+0.10)^{35}\right]$. Therefore, on average for every doctor that emigrates, a country loses about US\$1,854,677. Column 4 of Table 1 shows the economic loss incurred by each of the 14 countries as a result of brain drain of medical doctors. Those countries combined lost US\$35.165 billion as a result of emigration of 18960 medical doctors.

\section{Sensitivity analysis}

When we use an interest rate of $5 \%$ instead of $10 \%$, the returns from investing into a single doctor equals US $\$ 364,041$, i.e. $\left[U S \$ 65,997 \times(1+0.05)^{35}\right]$. The return from investment into 18960 doctors equals US $\$ 6,902,208,712$. The use of an interest rate of $5 \%$ instead of $10 \%$ reduces the amount of economic loss per doctor by 5 fold. Lets instead assume that the US $\$ 65,997$ is invested for 35 years at $15 \%$ interest rate. At that rate, the investment for one doctor would yield US\$8,789,187, i.e. [US\$65,997 x $(1+0.15)^{35}$ ]. Therefore, the use of an interest rate of $15 \%$ instead of $10 \%$ increases the amount of economic loss per doctor by 4.7 fold.

\section{Economic loss due to emigration of nurses}

The NMC is the regulatory body for nurses, midwives and specialist community public health nurses throughout the United Kingdom. About 18,349 nurses from the African Region were registered with the NMC between 1989/90 and 2004/2005. Approximately, 50.4\% were from South Africa; $14.5 \%$ from Nigeria; $12.6 \%$ from Zimbabwe; $7.2 \%$ from Ghana; $4.3 \%$ from Zambia; $3.5 \%$ from Kenya; and $7.4 \%$ from six other countries [10]. Although the actual number of emigrants may be less than those figures, they nevertheless give a rough idea of numbers of potential emigrants.

The tertiary cost of training one nurse in Kenyan school of health sciences is about US\$25,352. Since the cost of secondary education is US\$6,865 and that for primary education is US\$10,963, the total cost of educating one nurse is US\$43,180, i.e. US $\$ 25,352+\mathrm{US} \$ 6,865+\mathrm{US} \$ 10,963$. Assuming that the average age of emigrating nurses is 30 years; retirement age is 65 years in developed countries; an emigrant nurse would work for 35 years before retirement; and market interest rate on fixed deposit is $10 \%$. If the US $\$ 43,180$ (i.e. cost of educating one nurse) were put into a commercial bank for a period 
of 35 years, at a fixed deposit interest rate of $10 \%$ per annum, the investment will have grown to US\$1,213,463, i.e. [US\$43,180 x $\left.(1+0.10)^{35}\right]$. Therefore, on average for every nurse that emigrates, a country loses about US\$1.2 million. Table 2 presents estimates of cost of emigration of nurses from 12 African Region countries to the United Kingdom. Assuming all the 18,349 nurses from the African Region, who registered with the United Kingdom NMC between 1989/90 and 2004/2005, would emigrate that would result to an economic loss of US\$22.3 billion.

Table 1: Estimates of cost of migration of doctors in selected African Countries

\begin{tabular}{|c|c|c|c|}
\hline Countries & $\begin{array}{l}\text { Number of } \\
\text { doctors that } \\
\text { emigrated }\end{array}$ & $\begin{array}{l}\text { Cost of educating } \\
\text { medical doctors (US\$) }\end{array}$ & $\begin{array}{l}\text { Economic loss } \\
\text { incurred by each } \\
\text { country }(\mathrm{US} \$)^{2}\end{array}$ \\
\hline Angola & 145 & $9,569,565$ & $268,928,096$ \\
\hline Cameroon & 173 & $11,417,481$ & $320,859,039$ \\
\hline Ethiopia & 334 & $22,042,998$ & $619,461,959$ \\
\hline Ghana & 926 & $61,113,222$ & $1,717,430,462$ \\
\hline Guinea Bissau & 74 & $4,883,778$ & $137,246,063$ \\
\hline Kenya & 167 & $11,021,499$ & $309,730,980$ \\
\hline Liberia & 47 & $3,101,859$ & $87,169,797$ \\
\hline Mozambique & 47 & $3,101,859$ & $87,169,797$ \\
\hline Nigeria & 4,080 & $269,267,760$ & $7,567,080,221$ \\
\hline South Africa & 12,134 & $800,807,598$ & $22,504,644,950$ \\
\hline \begin{tabular}{|l} 
Tanzania \\
\end{tabular} & 112 & $7,391,664$ & $207,723,771$ \\
\hline Uganda & 316 & $20,855,052$ & $586,077,782$ \\
\hline Zambia & 168 & $11,087,496$ & $311,585,656$ \\
\hline Zimbabwe & 237 & $15,641,289$ & $439,558,336$ \\
\hline TOTAL & 18,960 & $1,251,303,120$ & $35,164,666,908$ \\
\hline
\end{tabular}

Note: ${ }^{1}$ This consists of the cost of primary, secondary \& tertiary education;

${ }^{2}$ Obtained by compounding the cost of training emigrating doctors over 35 years

\section{Sensitivity analysis of the interest rate}

If we used an interest rate of $5 \%$ instead of $10 \%$, the returns from investing in one nurse yields US $\$ 238,182$, i.e. [US\$43,180 x $(1+0.05)^{35}$ ]. The use of an interest rate of $5 \%$ reduces the amount of economic loss per nurse by 5.1 fold. Lets instead assume that the US\$43,180 is invested for 35 years at $15 \%$ interest rate. At that rate, the investment for one nurse would yield US $\$ 5,750,519$, i.e. [US $\$ 43,180 \mathrm{x}$ $\left.(1+0.15)^{35}\right]$. Therefore, the use of an interest rate of $15 \%$ increases the amount of economic loss per nurse by 4.7 fold.

\section{Sensitivity analysis of the number of emigrants}

It could be argued that not all nurses who register with the NMC would actually immigrate to the United Kingdom. Lets assume that only $18 \%$ of them would emigrate [11]. That means 3,303 nurses (i.e., $0.18 \times 18,349$ ) would have emigrated in seven years. Emigration of that number would lead to an economic loss of US\$4.01 billion.

\section{Discussion}

\section{Key findings}

The objective of this study was to estimate the social cost of emigration of doctors and nurses from the African Region to the developed countries. The key findings were as follows:

- The total cost of educating a single medical doctor from primary school to university is US\$65,997.

- On average for every doctor that emigrates, a country loses about: (i) US\$1,854,677, assuming a $10 \%$ interest rate; (ii) US\$364,041, assuming an interest rate of $5 \%$; (iii) US\$8,789,187, assuming an interest rate of $15 \%$.

- The total cost of educating one nurse from primary to college of health sciences is US\$43,180. 
- On average for every nurse who emigrates, a country loses about: (i) US $\$ 1,213,463$, assuming a $10 \%$ interest rate; (ii)
US $\$ 238,182$, assuming an interest rate of $5 \%$; (iii) US\$5,750,519, assuming an interest rate of $15 \%$.

Table 2: Estimates of cost of migration of nurses to the United Kingdom

\begin{tabular}{|l|r|r|r|}
\hline $\begin{array}{l}\text { Source } \\
\text { countries }\end{array}$ & $\begin{array}{l}\text { Total nurses registered } \\
\text { with UK nursing \& } \\
\text { midwifery council }\end{array}$ & $\begin{array}{l}\text { 1 } \\
\text { Cost of educating } \\
\text { nurses (US\$) }\end{array}$ & $\begin{array}{l}\text { Economic loss } \\
\text { incurred by each } \\
\text { country (US\$) }\end{array}$ \\
\hline South Africa & 9249 & $399,371,820$ & $11,223,321,350$ \\
\hline Nigeria & 2652 & $114,513,360$ & $3,218,104,468$ \\
\hline Zimbabwe & 2315 & $99,961,700$ & $2,809,167,361$ \\
\hline Ghana & 1326 & $57,256,680$ & $1,609,052,234$ \\
\hline Zambia & 790 & $34,112,200$ & $958,635,946$ \\
\hline Mauritius & 380 & $16,408,400$ & $461,116,025$ \\
\hline Kenya & 650 & $28,067,000$ & $788,751,095$ \\
\hline Botswana & 411 & $17,746,980$ & $498,733,385$ \\
\hline Swaziland & 150 & $6,477,000$ & $182,019,483$ \\
\hline Malawi & 309 & $13,342,620$ & $374,960,136$ \\
\hline Lesotho & 93 & $4,015,740$ & $112,852,080$ \\
\hline Sierra Leone & 24 & $1,036,320$ & $29,123,117$ \\
\hline TOTAL & 18,349 & $792,309,820$ & $22,265,836,681$ \\
\hline
\end{tabular}

Source: The Nursing and Midwifery Council.

Notes: ${ }^{1}$ Figures in this column consists of nurses that registered with the UK Nursing \& Midwifery Council between $1989 / 90 \& 2004 / 2005$. The assumption is that all of them emigrated. ${ }^{2}$ This consists of the cost of primary, secondary \& tertiary education; which is estimated at US $\$ 43,180 ;{ }^{3}$ The figures in this column are obtained by multiplying the cost of educating nurses by a relevant compounding factor $(1+r)^{t}=(1+0.10)^{35}$ to obtain future value in year 35 .

\section{Other losses from brain drain}

When the health professionals emigrate African countries lose far much more than the cost incurred by society to educate them. This is because there are several other losses that are not captured in the education costing methodology described in the Methods section. Some of those losses include:

Loss of health services: Usually the health professionals (especially doctors and nurses) contribute to health promotion, disease prevention, diagnosis, treatment and rehabilitation. The doctor and nurse population ratios in all the African countries are very low, and as a result medical practitioners and nurses are usually overloaded with patients [12]. Thus, emigration of doctors and nurses (and other health professionals) exacerbates the human resource shortage within national and district health systems and reduces their capability to perform their functions (of stewardship, health financing, resource/input creation and health service production and provision) and to achieve their goals of health improvement, responsiveness to client's legitimate expectations and fairness in financial contributions.

Loss of supervisors: Practising doctors and senior nurses normally play a major role in supervising staff in peripheral facilities (e.g. health centres, dispensaries and health posts) that serve majority of the populations. Thus, when such doctors and nurses emigrate the supervisory capability is lost (or diminished), contributing to further weakening of the capacities of such health facilities to provide quality services to patients. This compels the staff left behind to assume greater responsibilities than they trained for, invariably leading to decline in quality of health services.

Loss of mentors for health sciences trainees: Practising doctors (and senior nurses) trains and counsels (advises) new employees and students doing their internship. The emigration of either cadre has negative intergenerational effects on the process of health-related human capital creation in the African countries. 
Loss in functionality of referral systems: The hierarchical national referral system consists of tertiary hospitals (apex), provincial hospitals, district hospitals, health centres, dispensaries, health posts and community services. It permits movement of patients from the base of the national health system to the apex and vice-versa. Although the movement of patients should in principle be initiated by health professionals, in practice patients move themselves up and down this system. The patients bypass the cheapest health units (health centres, dispensaries and health posts) mainly due to lack of doctors and diagnostic services [13]. Those two factors create adverse incentives for patients to bypass the costeffective health units and to seek care in the more expensive hospitals. Thus, emigration of doctors contributes to inefficiency and weakening of referral systems.

Loss of role models: The children often view doctors and nurses practicing in communities as examples to be imitated/emulated. Thus, external migration not only robs such children of positive role models, but also negatively affects their dreams and aspirations, and hence numbers of children aspiring to become health professionals.

Loss of public health researchers: Many of the specialized doctors who emigrate are often among the very few active/published researchers that African countries have. Emigration of such people stifles innovation and invention into the persistent local public health problems, e.g. HIV/AIDS, tuberculosis and malaria.

Loss of custodian of human rights especially in rural areas: A recent study on status of national health research bioethics committees in the Region found that many countries do not have functional ethical review systems that protect the dignity, integrity and safety of citizens who participate in research [14]. Authors argue that health professionals who are posted in rural areas, by virtue of being the most educated, often bear the burden of assuring the human rights of their actual and potential clients are respected and protected in the course of their clinical work and research carried out by others.

Loss of savings (investment capital): In African countries, the health professionals are among the relatively well-paid persons, and thus they contribute to accumulation of national savings. Those savings are eventually loaned to entrepreneurs for investment. Thus, emigration may lead to loss of such savings, except where persons who emigrate remit their savings to their home countries for investment.
Loss of entrepreneurs: The health practitioners, by virtue of their education and earnings, quite often set up health-related (e.g. private clinics, hospitals, pharmacies) and non-health related businesses (e.g. retail and whole sale shops). Thus, emigration reduces the growth of entrepreneurship in affected countries and prospects for economic growth.

Loss of employment opportunities: Doctors and nurses usually provide job opportunities for housekeepers, gardeners and security guards within their places of residence. Thus, emigration of practising health professionals usually results in loss of employment opportunities and income for those poor workers and their families.

Loss of tax revenue to governments: Given that the health professionals are among the relatively wellpaid persons in African countries, they are also major contributors to the income tax. Since the incomes of emigrants are not amenable to tax administration systems of African countries, emigration leads to a net loss in tax revenues. That may not be a problem where emigration is bilaterally arranged between the donor and recipient countries; which is very rare phenomenon.

Disruption of families: In some instances due to emigration restrictions the emigrating health professionals are not allowed to move with their families. Due to spatial distance and loneliness some of those emigrants may be choose to get new marriage partners in their countries of work. This of course may bring psychological and economic suffering to the family members left behind in home countries.

Leads to "internal" brain drain: The brain drain, broadly construed, has not merely reduced the supply of vital health professionals available in the Region; perhaps even more serious, it has diverted the attention of those who remain from important local problems and goals [15]. These include provision of primary health care services (including health promotion and primary and secondary prevention of diseases) and the promotion of problem-oriented training and research on important domestic public health issues. Such needs are often neglected as training and research become dominated by richcountry ideas as to what represents true professional excellence. Those highly educated and highly skilled African health professionals who do not physically migrate to the developed countries nevertheless migrate intellectually in terms of the orientation of their activities. 


\section{Alternative methodology of measuring socio- economic loss of brain drain}

We propose the use of the economic concept of willingness to pay (WTP) to capture all the monetary and non-monetary benefits of investing in human resources for health. It is those benefits that the society stands to lose as a result of emigration. The approach entails determination of the maximum amount that each individual affected by brain drain (in the donor country) would be willing to pay to prevent an individual health professional from emigrating. The sum of every individual's maximum willingness to pay provides an estimate of the total benefits. The concept of WTP is powerful for two reasons: it does not place undue restrictions on the categories of benefits that can be considered; and its conceptual framework encompasses the benefits received by entire society (all stakeholders), and not just the patients $[16,17]$.

We have not come across usage of WTP in valuation of benefits that a society loses through brain drain. Contingent valuation is potentially a powerful method of estimating the value of difficultto-measure benefits mentioned in the last section. It relies on direct surveys to elicit WTP values from individuals. The contingent valuation approach uses either open-ended method, closed-ended iterative bidding method or "payment" cards [17]. The first method entails asking the individual to state their maximum willingness to pay to keep a health professional from emigrating. The second method asks individuals whether they would be willing to pay a specified amount to keep a health professional from emigrating. If they say 'Yes', the amounts are gradually increased and the question repeated until the answer is 'No'. The third method entails presenting a number of "payment cards" with different amounts to individuals and asking them to select the card with the maximum value that they would be WTP to prevent a health professional from emigrating. Please note that the use of the term "willingness" does not necessarily imply that individual respondents would be required to pay that amount. It is just a technique for revealing the value that society attaches to the investment embodied in health professionals.

The total socioeconomic loss per category human resources for health emigrating $=[$ sum of WTP values across all the persons interviewed / [total number of persons interviewed)] $x$ [Total population in a country] $x$ [Number of that category of staff that has emigrated]. Contingent valuation approach has been widely applied in the valuation of health benefits in Europe [18] and North America [19]. It has also been applied in Africa to value benefits of insecticide treated bed nets [20,21], community based health insurance [22,23] and health outcomes of Schistosomiasis interventions [24,25].

\section{Limitation of the study}

Our study has a number of limitations:

a) Due to data unavailability the study focuses on only two categories of health professionals (i.e. doctors and nurses) even though there is anecdotal evidence of brain drain among other cadres.

b) The cost estimates presented in this study are only for undergraduate programmes; while many of the doctors and nurses emigrating may have post-graduate qualifications. Thus, by not capturing the post-graduate investment we will have underestimated the cost of training, and hence, the lost returns from investment into post-graduate training.

c) The cost estimates also do not capture the anticipated increased salaries the doctors and nurses would have earned (e.g. as consultants/professors) in their 35 years or so of service.

d) The primary and secondary school education cost estimates used in this study were obtained from a single religious mission school. It is unlikely that such cost estimates would be representative of the cost of primary and secondary schooling in all countries of the region.

e) The nursing and doctor education cost estimates used in this study were from only one country's public university. These may not be representative of the cost of training nurses and doctors in the entire region. Definitely there is need to further studies in future that systematically estimate the cost of education in a more representative sample of countries, if not in all countries.

f) We used the number of nurses from selected African countries registered with the United Kingdom NMC (between 1998/99 and 2004/2005) as a proxy for the number of nurses that may have immigrated to the UK [10]. It could be argued that not all nurses who are registered with the NMC immigrate to the UK. We conducted sensitivity analysis on this assumption and the total losses of returns from educational investment remain huge.

\section{Suggestions for further research}

The following aspects are in need of further research: 
a) Monitor the temporal cost of loss of service, especially for key cadres such as specialist doctors and nurses, pharmacists and lecturers of medical and nursing schools.

b) Establish a database of cost of primary, secondary and tertiary education of various categories of human resources for health; and cost of alternative strategies for stemming the tide of brain drain.

c) Establish a programme for systematic monitoring of the international migration of different cadres of human resources for health and tracking of remittances of income.

d) Application of the contingent WTP approach in the valuation of socio-economic loss incurred by individual countries due to brain drain of different categories of human resources for health. Develop a database for such information.

e) Identify determinants of health staff motivation, including their health-related quality of life [26], and retention through regression analysis.

\section{Conclusion}

This study estimates economic loss incurred by African countries as a result of emigration of one doctor to be about US\$1,854,677 and one nurse to be US\$1,213,463. The United Nations Commission for Trade and Development (UNCTAD) estimated that each migrating African professional represents a loss of US $\$ 184,000$ [1]. Thus, our study estimates that losses to Africa as a result of emigration of a single medical doctor are ten times the UNCTAD estimate.

We suspect that the magnitudes of socioeconomic losses due to brain drain are likely to be even larger than our estimates. Therefore, there is need for more precision in the measurement of the magnitudes of the socioeconomic loss due to brain drain, for use in advocacy and policy. We propose the use of Contingent Valuation to measure the benefits from investments into specific categories of human resources for health. Those benefits would be a more accurate indicator of the losses incurred by African countries due to brain drain.

Developed countries continue to rob African countries of billions of dollars worth of invaluable investments embodied in their human resources. If the current trend of poaching of the scarce human resources for health (and other forms of human resources) from African countries is not curtailed, the chances of achieving the Millennium Development Goals would remain dismal. Since limited human resources for health are the head, heart and hands of national and district health systems [27], the continued plunder of investments embodied in human resources contributes: to the growing double burden of communicable and non-communicable diseases (by weakening health promotion and primary and secondary prevention); to further underdevelopment of Africa; and to keeping African people in the vicious cycle of poverty. That is both immoral and unethical!

Economic arguments not withstanding, ultimately, the price of emigration of human resources for health from the African countries to developed nations is paid in unnecessary debility, morbidity, human suffering and premature deaths among African people. This unacceptable situation should be urgently reversed through joint action from both developing and developed countries.

\section{Acknowledgements}

We are grateful to the University of Nairobi (Medical School and College of Health Sciences) and Loreto Msongari Primary and Secondary School for having provided the cost data that has been used in this study. We are grateful to Joe Kadhi for editorial help. Finally, we are immensely grateful to Jehovah Jireh for having inspired us to undertake the study. The article contains the analysis and views of the authors and does not represent the decisions or stated policies of the World Health Organization or the Kenyatta University.

\section{References}

1. Pang T, Lansang MA and Haines A. Brain drain and health professionals. British Medical Journal. 2002; 324:499-500.

2. Kupfer L, Hofman K, Jarawan R, McDermott J and Bridbord K. Strategies to discourage brain drain. Bulletin of the World Health Organization. 2004; 82:616-623.

3. Awases M, Gbary A and Chatora R. Migration of health professionals in six countries: a synthesis report. Brazzaville: WHO Regional Office for Africa. 2004. 67p.

4. Stilwell B, Diallo K, Zurn P, Vujicic M, Adams $\mathrm{O}$ and Poz MD. Migration of healthcare workers from developing countries: strategic approaches to its management. Bulletin of the World Health Organization. 2004; 82:595-600.

5. United Nations. Millennium Development Declaration. New York: UN. 2000; 9p

6. United Nations Development Programme. Human Development Report 2004: cultural liberty in today's diverse world. New York: UNDP. 2004; 283p 
7. Drummond MF, Stoddart GL and Torrance GW. Methods for the economic evaluation of health care programmes. Oxford University Press. 1997; 182p.

8. Kirigia JM. Cost-utility analysis of schistosomiasis intervention strategies in Kenya. Environment and Development Economics. 1998; 3:319-346.

9. Kirigia JM, Snow RW, Fox-Rushby J and Mills A. The cost of treating paediatric malaria admissions and the potential impact of insecticide treated mosquito nets on hospital expenditure. Tropical Medicine and International Health. 1998; 3:145-150.

10. The Nursing and Midwifery Council. Statistical analysis of the register. London: United Kingdom. 2005. Electronically available at www.nmc-uk.org.

11. Jantjie $\mathrm{X}$ and Philips G. Understanding nurse emigration: final report. Johannesburg: Trade Union Research Project. $11 \mathrm{p}$ (not dated)

12. World Bank. Better health in Africa: experience and lessons learned. Washington, D.C. World Bank. 1994. 240p

13. Mwabu GM. Referral systems and health care seeking behaviour of patients: an economic analysis. World Development. 1989; 17:85-92.

14. Kirigia JM, Wambebe C and Baba-Moussa A. Status of national research bioethics committees in the WHO African Region. BMC Medical Ethics. 2005; 6:10. Available at http://www.biomedcentral.com/14726939/6/10.

15. Todaro MP. Economic Development. New York: Addison-Wesley. 2000; 347p.

16. Levin HM and McEwan PJ. Costeffectiveness analysis: methods and applications. London, Sage Publications, Inc.; 2001; 307p.

17. Russell S, Fox-Rushby J and Arhin DC. Willingness and ability to pay for health care: a selection of methods and issues. Health Policy and Planning. 1995; 10:94101.

18. Gyldmark M and Morrison GC. Demand for Health Care in Denmark: Results of a national sample survey using contingent valuation. Social Science and Medicine. 2001; 53:1023-1036.

19. Morrison GC: Willingness to Pay and Willingness to Accept: Some evidence of an endowment effect. Applied Economics. 1997; 29:411-417.
20. Onwujekwe OE, Chima R, Shu E, Nwagbo DFE, Akpala $\mathrm{C}$ and Okonkwo P. Altruistic willingness to pay in community-based sales of Insecticide-treated nets exists in Nigeria. Social Science and Medicine. 2002; 54:519527.

21. Onwujekwe OE. Searching for a better contingent valuation elicitation method in rural Nigeria. The Binary question with follow-up versus the bidding game technique. Health Economics. 2001; 10:147158.

22. Abel-Smith B and Rawal P. Employer's willingness to pay: the case for compulsory health insurance in Tanzania. Health Policy and Planning. 1994; 9:409-418.

23. Asenso-Okyere WK, Osei-Akoto I, Anum A and Appiah EN. Willingness to pay for health insurance in a developing economy. A pilot study of the informal sector of Ghana using contingent valuation. Health Policy. 1997; 42:223-237.

24. Kirigia JM, Sambo LG and Kainyu LH. A cost-benefit analysis of preventive schistosomiasis interventions in Kenya. African Journal of Health Sciences. 2000; 7: 5-11.

25. Munguti N and Kirigia JM. Health Related Qualify of Life Among Health Care Personnel in Groot Schuur Hospital. African Journal of Health Sciences. 1998; 5:185189.

26. Mercer H, Poz MD, Adams O, Stiwell B, Buchan J, Dreesch N, Zurn P and Beaglehole R. Human resources for health: developing policy options for change. In: Ferrinho P and Poz MD (Editors). Towards a global health workforce strategy. Antwerp: ITG Press. 2003; pp.451-482. 
Appendix 1: Mission primary school cost per student

\begin{tabular}{|r|r|r|r|r|r|}
\hline \multicolumn{7}{|c|}{$\begin{array}{l}\text { Tuition } \\
\text { Yeart per } \\
\text { year }\end{array}$} & $\begin{array}{l}\text { Lunch } \\
\text { cost per } \\
\text { year }\end{array}$ & $\begin{array}{l}\text { Transport } \\
\text { cost per } \\
\text { year }\end{array}$ & $\begin{array}{l}\text { Cost of textbook+ } \\
\text { stationary+ } \\
\text { uniforms }\end{array}$ & $\begin{array}{l}\text { Sub-total } \\
\text { costs (Ksh) }\end{array}$ \\
\hline 1 & 54300 & 19500 & 15000 & 7000 & 95800 \\
\hline 2 & 54300 & 19500 & 15000 & 7000 & 95800 \\
\hline 3 & 54300 & 19500 & 15000 & 7000 & 95800 \\
\hline 4 & 54300 & 19500 & 15000 & 7000 & 95800 \\
\hline 5 & 57300 & 19500 & 15000 & 7000 & 98800 \\
\hline 6 & 57300 & 19500 & 15000 & 7000 & 98800 \\
\hline 7 & 57300 & 19500 & 15000 & 7000 & 98800 \\
\hline 8 & 57300 & 19500 & 15000 & 7000 & 98800 \\
\hline Total Cost $($ Ksh) & $\mathbf{4 4 6 4 0 0}$ & $\mathbf{1 5 6 0 0 0}$ & $\mathbf{1 2 0 0 0 0}$ & $\mathbf{5 6 0 0 0}$ & $\mathbf{7 7 8 4 0 0}$ \\
\hline Total Cost (US\$) & $\mathbf{6 2 8 7}$ & $\mathbf{2 1 9 7}$ & $\mathbf{1 6 9 0}$ & $\mathbf{7 8 9}$ & $\mathbf{1 0 9 6 3}$ \\
\hline
\end{tabular}

Appendix 2: Mission secondary school cost per student

\begin{tabular}{|c|c|c|c|c|c|}
\hline Year & \begin{tabular}{|l|} 
Tuition \\
cost per \\
year
\end{tabular} & \begin{tabular}{|l|} 
Lunch \\
cost per \\
year
\end{tabular} & $\begin{array}{l}\text { Transport } \\
\text { cost per } \\
\text { year }\end{array}$ & $\begin{array}{l}\text { Cost of textbooks+ } \\
\text { stationary+ } \\
\text { uniforms }\end{array}$ & $\begin{array}{l}\text { Subtotal } \\
\text { Costs (Ksh) }\end{array}$ \\
\hline & 74300 & 19500 & 15000 & 14000 & 122800 \\
\hline & 71300 & 19500 & 15000 & 14000 & 119800 \\
\hline & 71300 & 19500 & 15000 & 14000 & 119800 \\
\hline & 76500 & 19500 & 15000 & 14000 & 125000 \\
\hline Total Cost (Ksh) & 293400 & 78000 & 60000 & 56000 & 487400 \\
\hline Total Cost (US\$) & 4132 & 1099 & 845 & 789 & 6865 \\
\hline
\end{tabular}

Appendix 3: College of health sciences program cost per nursing student

\begin{tabular}{|c|c|c|c|}
\hline Year & \begin{tabular}{|l|} 
Tuition \\
Cost \\
Per year
\end{tabular} & $\begin{array}{l}\text { Accommodation+ } \\
\text { Living expenses }\end{array}$ & $\begin{array}{l}\text { Sub-total cost } \\
(\text { Ksh })\end{array}$ \\
\hline 1 & 240000 & 120000 & 360000 \\
\hline 2 & 240000 & 120000 & 360000 \\
\hline 3 & 240000 & 120000 & 360000 \\
\hline 4 & 240000 & 120000 & 360000 \\
\hline 5 & 240000 & 120000 & 360000 \\
\hline Total Cost (Ksh) & 1200000 & 600000 & 1800000 \\
\hline Total Cost (US\$) & 16901 & 8451 & 25352 \\
\hline
\end{tabular}

Note: The statistics in this table represent unsubsidized cost. 
Appendix 4: Public university parallel programme cost per medical doctor

\begin{tabular}{|c|c|c|c|}
\hline Year & \begin{tabular}{|l} 
Tuition \\
Cost \\
Per year
\end{tabular} & $\begin{array}{l}\text { Accommodation+ } \\
\text { living expenses }\end{array}$ & Sub-total cost $($ Ksh $)$ \\
\hline 1 & 450000 & 120000 & 570000 \\
\hline 2 & 450000 & 120000 & 570000 \\
\hline 3 & 450000 & 120000 & 570000 \\
\hline 4 & 450000 & 120000 & 570000 \\
\hline 5 & 450000 & 120000 & 570000 \\
\hline 6 & 450000 & 120000 & 570000 \\
\hline Total Cost (Ksh) & 2700000 & 720000 & 3420000 \\
\hline Total Cost (US\$) & 38028 & 10141 & 48169 \\
\hline
\end{tabular}

Note: The statistics in this table represent unsubsidized cost. 
Figure 1: Health professionals production process and benefits

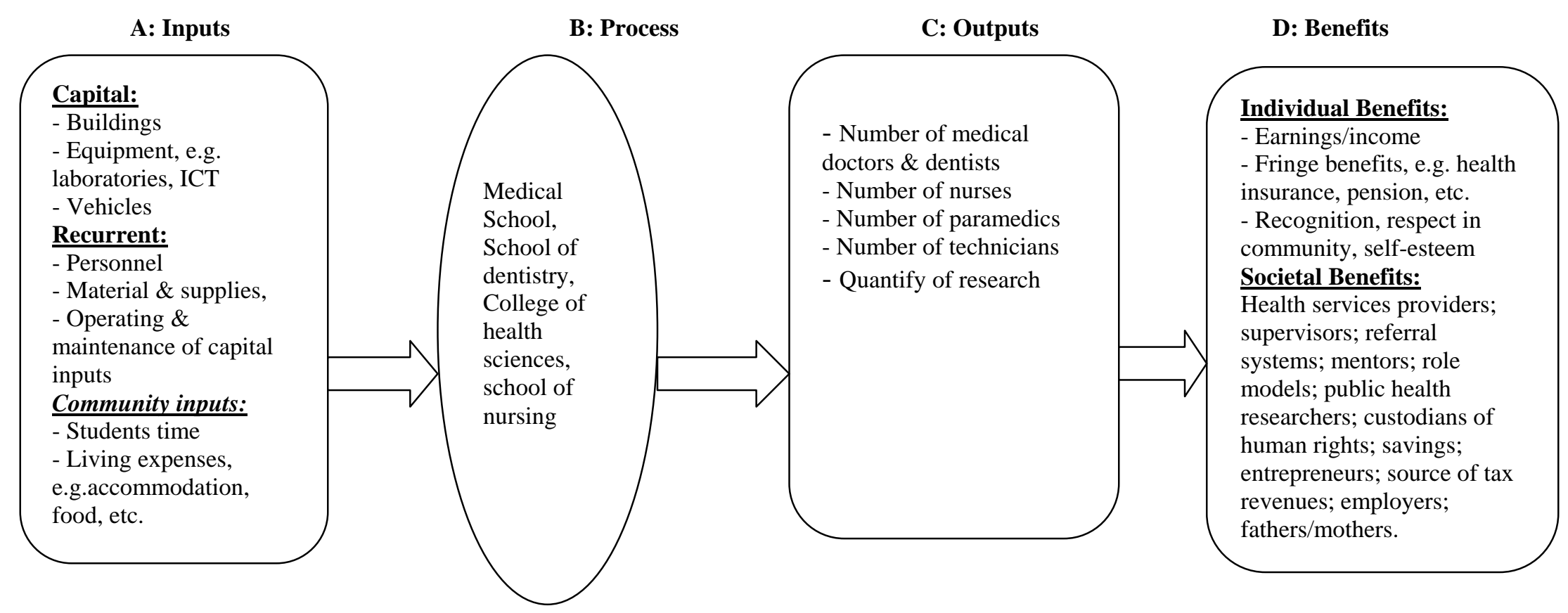

